\title{
CORRESPONDENCE
}

\begin{tabular}{|c|c|c|}
\hline 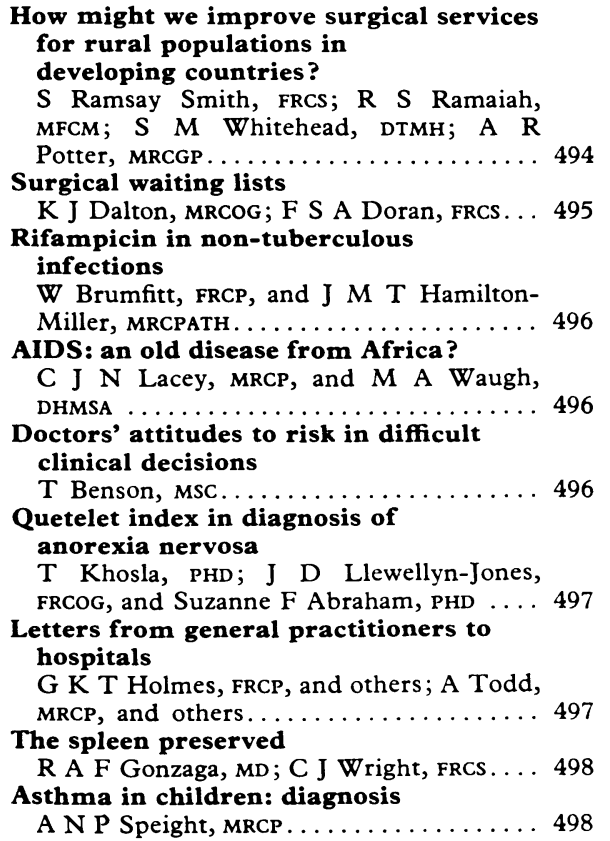 & $\begin{array}{l}\text { trimoxazole } \\
\text { s } \\
\ldots \ldots \ldots \ldots \ldots \\
\text { imicking } \\
\text { hers; D Slater, } \\
\ldots \ldots \ldots \ldots \ldots 4 \\
\text { pulsatile } \\
\text { asing } \\
\ldots \ldots \ldots \ldots \\
\text { ng }\end{array}$ & V \\
\hline
\end{tabular}

We may shorten letters to the editor unless the authors specifically state that we may not. This is so that we can offer our readers as wide a selection of letters as possible. We receive so many letters each week that we have to omit some of them. Letters must be typed with double spacing between lines and must be signed personally by all their authors, who should include their degrees. Letters critical of a paper may be sent to the authors of the paper so that their reply may appear in the same issue.

\section{How might we improve surgical services for rural populations in developing countries?}

SIR,-The articles by Professor Samiran Nundy (14 July, p 71) and Dr Erik M Nordberg (14 July, p 92) on the severe shortcomings in surgical services in the poorer countries of the world and the article by Dr J Muir Gray (14 July, $p$ 106) referring to the inadequacies in the health service provided in England are closely related. It was the realisation on my return from five years in Africa that there was no longer any place for me as a consultant surgeon in the NHS that helped to crystallise my feelings about doctors' roles in health care. Seven of us who graduated from Liverpool in 1971 turned to a career in surgery after qualifying, and not one to my knowledge has a permanent senior registrar post in general surgery. Yet in Lesotho I was one of only four qualified surgeons in a country of over a million inhabitants.

What sort of system can it be which allows myself and 200 others to be effectively redundant while accepting that surgical services in many countries are desperately short of exactly the same energy and expertise which is presently being wasted in this country?

Furthermore, I would ask Professor Nundy whether he prefers the sight of unsightly lumps and bumps to that of thousands of children dying simply from lack of access to clean water. I was surprised that neither surgical article referred to the enormous possibilities which the education of non-medically qualified people may contribute towards the solution of these ubiquitous, severe, and avoidable (in many cases) problems. There is every advantage to be gained from a surgeon/ obstetrician training traditional birth attendants in the villages; in the same manner al doctors working in the poorer countries should spend time and energy educating their communities in ways in which they may increase their access to clean water. It is no enough for surgeons to concern themselves only with the end results of preventable diseases, and it is no longer enough for us as medically orientated individuals to concern ourselves with our own chosen specialty.

While I agree with Professor Nundy and Dr Nordberg, I do not think that the answers they have proposed are likely to work in practice. If any solution is to be found it will have to take into account the meagre resources allocated to health care and surgery. Furthermore, the fact that neither article gave any serious consideration to the preventive aspects of surgical care in rural areas is indicative of a prevailing attitude in surgeons generally. I can illistrate this point more clearly by describing one of the methods we adopted to extend the surgical service provided by our hospital in Lesotho.

Burns cases represent a high proportion of surgical intake in all countries. Most cases arise as a result of preventable accidents in the home. Even if we go out to villages and schools in order to spread the gospel of accident prevention practical problems often prevent the message being acted on. In January this year we used the hospital as the base for a week long course on how to build and use a Lorena stove; this was well attended by various people throughout the local community and within three months we had news that these same stoves were starting to be built even in remote villages. From a preventive, surgical view the advantage of these stoves is that they are completely stable and there is little chance of young children being burnt by them. They are also of great practical advantage to the community - for example, in conserving fuel. The lesson from this is that a high degree of involvement of the local community should be considered an essential part of any plans we may have for trying to improve surgical care in rural areas.

My very first sight of an operating theatre in rural Africa was in 1964 in a mission hospital deep in the southern rain forest of Cameroon. The sight of seven operating tables in full swing was awe inspiring and was made more so when I realised that only two tables were being used by doctors. All others were occupied by clinical officers who had been trained by the doctors to operate under supervision. I believe in the use of non-medically qualified staff to assist with the heavy surgical load. I do no think that we have the right to blame politicians and administrators until we as surgeons and doctors can honestly say that we have at least made some attempt to make better use of resources.

My experience in Africa has shown me the inappropriate nature of much of the surgical teaching in academic institutions, but I fear that the generally conservative nature of those in charge is unlikely to allow change. It is sad that much of the benefit which may have been gained from tertiary education in the industrialised countries has been masked by an 
adherence to teachings which may not be appropriate to the needs of the student's own country

It would be comforting to know that there was a body responsive to the health needs of the world which could begin to use the vast wealth of experience, materials, and technology for the needs of the large proportion of the world's population. The World Health Organisation can claim credit for some successes, but there is much it could do to improve surgical services to the poorer countries by encouraging more liaison between the rich and the poor nations.

SAM RAMSAY SMITH

Brighton BN2 5TG

SIR,-For too long Third World governments have concentrated on providing services for urban populations. One can understand this policy since city dwellers are the most vociferous, literate, and political. Any unrest among them may be a bad omen for these governments. Only in recent years have governments shown any interest in rural populations-especially as regards health care.

Although I agree with Professor Samiran Nundy (14 July, p 71), my worry is that the decision makers may choose the wrong priorities. Instead of concentrating on basic needs they may advocate sophisticated and expensive measures modelled on Western countries. These measures may be a luxury in Third World countries. There is an acute need to develop an infrastructure in primary health care before establishing secondary services.

In terms of achieving common good for large rural populations this is the best way forward. Unfortunately, many of the health care decision makers are preoccupied with the glamorous institutions to which Professor Nundy refers. A drastic change in this attitude is needed to improve the services for the rural populations. The main emphasis has to be on rural health care.

\section{Department of Community Medicine, \\ Clwyd Health Authority,
Mold, Clwyd CH7 1PZ \\ Ramaiah RS. Clinical epidemiology in the Third World Lancet 1982;ii:220.}

SIR,-I have recently been working in a hospital in rural Kenya that was the main health facility for a population of around 200000 . None of the four doctors working there had had a formal training in surgery, but all of us had learnt by experience to deal with common surgical emergencies. Very little cold surgery was undertaken. We did our best with occasional spectacular successes and occasional disasters. I often felt that I was working very close to and maybe beyond the limits of my surgical skill and experience and often regretted that the only way to learn was the hard way.

Undoubtedly the hospital, the doctors, and the patients would benefit from a trained surgeon. Local surgeons are generally not keen to live and work in remote rural areas, preferring the higher salaries and better living standards offered by the bigger towns. In any case their numbers are few compared with the need. Expatriate surgeons, while paying lip service to the wonderful experience to be gained in the developing world, are unwilling to jeopardise their career prospects by working abroad.
I suggest that there is a place for short term attachments to the developing world for surgeons from training centres in the developed world. This must be a sustained and regular commitment from the centre of excellence to the small rural hospital, and the surgeon should be well briefed about the problems he is likely to meet. Surgical care will improve as the longer term doctors are encouraged to increase their surgical skills; the local population will benefit from the establishment of a good quality surgical service; and the surgeon will benefit from the challenge of rural surgery.

S M WHITEHEAD

Hemingford Grey, Cambs

SIR,-Professor Samiran Nundy is right to emphasise that much surgery in the Third World can be competently performed by doctors with a "fairly rudimentary training in surgery." Dr Erik Nordberg also emphasises this (14 July, p 92) by highlighting the importance of three common conditions requiring surgery. My 10 year review of surgery at a rural mission hospital in West Africa ${ }^{1}$ showed that hernia repair, lapaorotomy, and strangulated hernia repair accounted for $58^{\circ}{ }_{0}$ of general surgical procedures, whereas thyroidectomy, prostatectomy, and mastectomy accounted for less than $0 \cdot 5^{\circ}{ }_{0}$ each. ${ }^{1}$

Rural government hospitals and mission hospitals are often staffed by young doctors. I am concerned that they should be prepared before reaching these demanding assignments. Certainly such doctors should be ready to learn necessary operative skills-often from "unqualified" medical assistants. When I visited several remote hospitals in Northern Zaire earlier this year I met African nurses who had taken training in surgery and were achieving commendable results. British doctors contemplating service overseas should if at all possible have up to date experience in general surgery, obstetrics, gynaecology, and accident and emergency work. ${ }^{1}$ Six months in each of these specialties, even at a junior level, would be a suitable foundation for work in the Third World. "We should like to see it widely accepted in this country that a professional career should normally include a period of work overseas in a developing country."2

\section{ANDREW R POTTER}

Kent and Sussex Hospital

Tunbridge Wells, Kent TN4 8AT 'Potter AR. Surgery in an African bush hospital. Med $\mathcal{F}$
Aust 1982 ;ii $469-71$.
' King M, ed. Medical care in developing countries
Oxford: Oxford University Press, 1966.

\section{Surgical waiting lists}

SIR,-I learnt a salutary lesson about waiting lists (4 August, p 271) three years ago when I was a junior doctor at St Elsewhere's Hospital in another part of the country. The area health authority (as was) had produced a mountain of official statistics which purported to show a long waiting time for gynaecological operations. Knowing that our unit's practice was to give the patient a date for surgery at the initial consultation, I was at a loss to explain how the waiting list could be so long. I queried the figures with the information office which had produced them, and I was told that the figures were correct. How dare I question them.
Undaunted I pressed on and requested a list of all patients reputed to be waiting longer than six months for a gynaecological operation. A cursory glance through the list of names showed that some women featured as many as three times. One poor woman had been waiting over nine months for an operation to terminate her pregnancy and another had been waiting 15 months.

Taking just one consultant's waiting list as a sample, I examined the case notes of all those patients said to have been on the list for over six months. Most had either had their operation already or had notified their intention of not proceeding with the operation, and yet their names had not been removed from the official waiting list. Not even one patient on the list was genuinely waiting for her operation.

As I did not examine in any detail the waiting lists of the other consultants, I cannot say to what extent my findings were representative of the area waiting list as a whole. Doubtless some patients do genuinely wait a long time for an operation. Nevertheless, I strongly suspect that I had uncovered the tip of a large iceberg of spurious statistics.

Some while afterwards these same dubious waiting list statistics were quoted in the House of Commons by one of the local members of parliament in support of one particular cause he was espousing. I do not doubt that he quoted them in good faith. As the question of waiting lists seems to fuel so much angry debate is it not time for us to provide our politicians (both local and national) with valid statistics about which they may then argue at leisure? Valid statistics would no doubt pave the way for a better deployment of our limited health resources, which would in turn help those patients who genuinely do wait a long time for operations.

I propose that we invent a new specialtythat of the medically qualified "consultant queueologist." He could tackle not only surgical waiting lists, but also outpatient waiting lists and clinic waiting times. If he could solve the problems his salary would be money well spent.

Kevin J Dalton

University of Cambridge Clinica

School Department of

Obstetrics and Gynaecology,

Rosie Maternity Hospital,

SIR,-I have recently completed a report on waiting lists, and rightly Dr David Morris (4 August, p 271) complains that the official statistics do not give an accurate impression of NHS waiting lists.

The surgical waiting list (including gynaecology) is $96^{\circ}$ of the total waiting list; and $78 \%$ of that surgical list consists of patients waiting for general surgery, trauma and orthopaedic surgery, ear, nose, and throat surgery, and gynaecological treatment in that order. Furthermore, there is no doubt that numerically, $70 \%$ of the current waiting list was inherited in 1948-9 and has hung like a millstone round the neck of the hospital service ever since.

As calculated from data collected individually from each of the 22 administrative districts in the West Midlands region the numbers of patients waiting for general surgery, trauma and orthopaedic surgery, ear, nose, and throat surgery, and gynaecological treatment alone represent work for more than double the number of operating theatres that now exist in the West Midlands. If 17 extra theatres were built in each of the 14 English regions it would 